\title{
Effects of Different Final Irrigating Solutions on Depth of Sealer Penetration into Dentinal Tubules: An in vitro Confocal Laser Microscopic Study
}

\author{
${ }^{1}$ Madhavi A Shetty, ${ }^{2}$ Vibha Hegde
}

\begin{abstract}
Aim: To evaluate the maximum depth of sealer penetration into dentinal tubules at the coronal, middle, and apical third of root canals, following the use of different final irrigation solutions.

Materials and methods: Eighty freshly extracted mandibular premolars were selected for the study. After decoronation, instrumentation of samples was done using Protaper universal rotary file system till F4. During shaping and cleaning of root canal, 5.25\% concentration of sodium hypochlorite $(\mathrm{NaOCl})$ was used for irrigation. The samples were then randomly divided into four groups $(n=20)$ depending on the final irrigating solution used. Group I: $17 \%$ aqueous ethylenediaminetetraacetic acid (MA) (aq. EDTA); group II: $10 \%$ citric acid (CA); group III: $5 \%$ maleic acid; group IV: $5.25 \%$ conc. NaOCl. Passive ultrasonic irrigation (PUI) was used to activate each final irrigating solution. The samples were obturated using warm lateral condensation technique with guttapercha coated with $\mathrm{AH}$ plus sealer mixed with rhodamine $\mathrm{B}$ dye. Confocal laser scanning microscopy (CLSM) examined the sealer penetration depth.
\end{abstract}

Results: The Kruskal-Wallis analysis results showed that there was a significant difference in the maximum depth of sealer penetration among all groups in all sections $(p<0.05)$. The coronal sections of the root canals in each group showed a significantly higher depth of sealer penetration than did the apical and middle sections $(p<0.05)$.

Conclusion: A combination of $17 \%$ aq. EDTA and PUI used for final irrigation proved to be more effective for sealer penetration into the dentinal tubules.

Clinical significance: Final irrigation protocol followed is of paramount importance in achieving complete disinfection within the root canal, and also the penetration of sealer serves as an indicator of the extent to which the smear layer was removed.

Keywords: Citric acid, Dentinal tubules, Ethylenediaminetetraacetic acid, Final irrigation, Sealer penetration.

How to cite this article: Shetty MA, Hegde V. Effects of Different Final Irrigating Solutions on Depth of Sealer Penetration into

\footnotetext{
${ }^{1}$ Postgraduate Student, ${ }^{2}$ Professor and Head

1,2Department of Conservative Dentistry and Endodontics, YMT Dental College \& Research Institute, Mumbai, Maharashtra India

Corresponding Author: Madhavi A Shetty, Postgraduate Student, Department of Conservative Dentistry and Endodontics YMT Dental College \& Research Institute, Mumbai, Maharashtra India, Phone: +919819550368, e-mail: drmadhavishetty@ gmail.com
}

Dentinal Tubules: An in vitro Confocal Laser Microscopic Study. J Oper Dent Endod 2017;2(2):69-73.

Source of support: Nil

Conflict of interest: None

\section{INTRODUCTION}

The endodontic triad for successful root canal therapy comprises shaping and cleaning, disinfection followed by three-dimensional (3D) obturation of the root canal system. ${ }^{1}$ The aim of endodontic treatment is to eliminate microorganism, vital and necrotic tissue from the root canal system, and to prevent recontamination. ${ }^{1}$ The complex anatomy of the root canal system, such as lateral canals, ramifications, and deltas, makes it impossible to completely disinfect the root canal using instrumentation alone. Hence, irrigation is a crucial complement to instrumentation because it penetrates these canal irregularities and disinfects the root canal system efficiently. ${ }^{2}$ The removal of the smear layer, which contains attached microbiota and their toxins from canal walls, improves the seal of the obturating materials with the dentinal walls and reduces the potential for survival and reproduction of microorganisms. ${ }^{3}$ The depth of sealer penetration into the dentinal tubules might serve as an indicator of the extent to which the smear layer was removed. ${ }^{2}$ Chelating agents, such as ethylenediaminetetraacetic acid (EDTA), CA, MA, phosphoric acid, and combinations of EDTA and $\mathrm{NaOCl}$ have been used to remove the smear layer. ${ }^{4} \mathrm{~A}$ chelating agent helps in removing the smear layer by forming a coordinate bond with metallic ions of the organic compound. ${ }^{5}$ Therefore, they could be used as the final rinse in root canals after completion of instrumentation; $17 \%$ EDTA has been the most highly recommended chelating agent used for this purpose. ${ }^{6}$ Several weak acids, such as CA, MA, and apple cider vinegar, have been reviewed at different concentrations for the removal of smear layer. ${ }^{7}$ The effect of irrigation and smear layer removal depends on different techniques and irrigant delivery devices which improve the flow and distribution of irrigating solutions within the root canal system, such as manual agitation devices, sonic and ultrasonic devices, rotary brushes, and pressure alternation devices. ${ }^{8}$ The analysis of the dentin/sealer interface 
allows the determination of which materials and filling techniques could obturate the root canals with less gaps and voids. ${ }^{9}$ In comparison to conventional scanning electron microscope (SEM), CLSM has the advantage of providing detailed information about the presence and distribution of sealers or dental adhesives inside dentinal tubules in the total circumference of the root canal walls at relatively low magnifications $100 \times$ through the use of fluorescent rhodamine-marked sealers. ${ }^{10}$ Hence, this study was undertaken to evaluate the maximum depth of sealer penetration following the use of different final irrigations solutions (17\% aq. EDTA, 7\% MA, and 10\% CA) at the coronal, middle, and apical third of the root canal, activated by PUI, obturated using AH Plus sealer, and analyzed using a CLSM.

\section{MATERIALS AND METHODS}

Human mandibular premolars freshly extracted (for orthodontic treatment) with a single straight canal and fully formed apices were selected, and confirmation of single canal was carried out by buccolingual and mesiodistal angulated radiographs. The teeth samples were decoronated with a diamond disk under water to a length of $16 \mathrm{~mm}$. Hand instrumentation was done until \#25k-file. The samples were instrumented by Protaper universal until full sequence F4 (40/0.06). During shaping and cleaning, EDTA gel was used as lubricant and $5.25 \% \mathrm{NaOCl}$ was used for irrigation between each file change and recapitulation. After instrumentation the canals were dried using sterile absorbent paper points and the samples were prepared to receive final irrigation.

\section{Distribution of Teeth for Final Irrigation}

The teeth were randomly divided into the following four groups $(n=20)$, according to the final irrigants used: Group I: Final irrigation with $17 \%$ aq. EDTA. Group II: Final irrigation with 10\% CA. Group III: Final irrigation with 5\% MA. Group IV: Final irrigation with 5.25\% $\mathrm{NaOCl}$ (control group). For all the groups the sequence includes $2 \mathrm{~mL}$ of $5.25 \% \mathrm{NaOCl}$ for 1 minute followed by drying with sterile paper points; then using the different final irrigating solutions. Passive ultrasonic activation was performed using a stainless steel, noncutting, ultrasonic IrriSafe \#20/25 mm file tip (Satelec, Acteon group, Merignac, France) mounted on a Suprasson P5 Booster ultrasonic unit (Satelec) at a power setting of five. The file was inserted passively $1 \mathrm{~mm}$ short of the working length and was activated for a period of 1 minute for each final irrigant used with a total volume of $5 \mathrm{~mL}$ per irrigant. This is followed by a final rinse of $5 \mathrm{~mL}$ of $5.25 \% \mathrm{NaOCl}$ for 1 minute.

\section{Obturation Protocol for Prepared Samples after Final Irrigation Procedure}

All teeth were obturated with AH Plus sealer and guttapercha using lateral compaction technique. For fluorescence under confocal laser microscopy, AH Plus sealer was used by mixing with $0.1 \%$ fluorescent rhodamine B isothiocyanate. Sealer was applied with a lentulo spiral and the root canals were filled with accessory gutta-percha cones of size 30 with a 0.02 taper. Excess gutta-percha was removed using a heated plugger. The decoronated teeth samples were sealed using Cavit and stored in an incubator at $370^{\circ} \mathrm{C}$ and $100 \%$ humidity for 24 hours to allow sealer to set.

\section{Confocal Analysis}

Samples from each treatment group were then divided into apical sections ( $3 \mathrm{~mm}$ from the apex), middle sections ( $5 \mathrm{~mm}$ from the apex), and coronal sections $(8 \mathrm{~mm}$ from the apex). The prepared specimens were mounted onto glass slides and examined with a Leica TCS-SPE confocal microscope. Each sample image was imported into Image J. Areas along the canal walls in which the sealer penetrated into dentinal tubules were outlined and measured using the measuring tool in the Image J software. For measuring the depth of penetration, the point of deepest penetration was measured from the canal wall to the point of maximum sealer penetration into the dentinal tubules (Fig. 1).

\section{Statistical Analysis}

Descriptive statistical data of CLSM scores of the study groups were recorded (Table 1). Statistical analysis was performed using the Kruskal-Wallis nonparametric test for comparisons between groups (Table 2). The Dunn's test for multiple comparison (also a nonparametric analysis) was used for comparisons within groups (Table 3). The level of significance was set at $\mathrm{p}<0.05$.

\section{RESULTS}

- The results of this study showed that chelating agents like $17 \%$ aqueous EDTA showed significantly superior depth of sealer penetration compared with $10 \%$ CA (Graph 1).

- They showed significantly better depth of sealer penetration compared with 7\% MA.

- All the mentioned chelating agents proved significantly superior to $\mathrm{NaOCl}$ when activated by PUI.

- Also the coronal sections showed more sealer penetration followed by middle and apical.

- The apical sections of EDTA and CA showed similar depth of sealer penetration (Graph 1). 

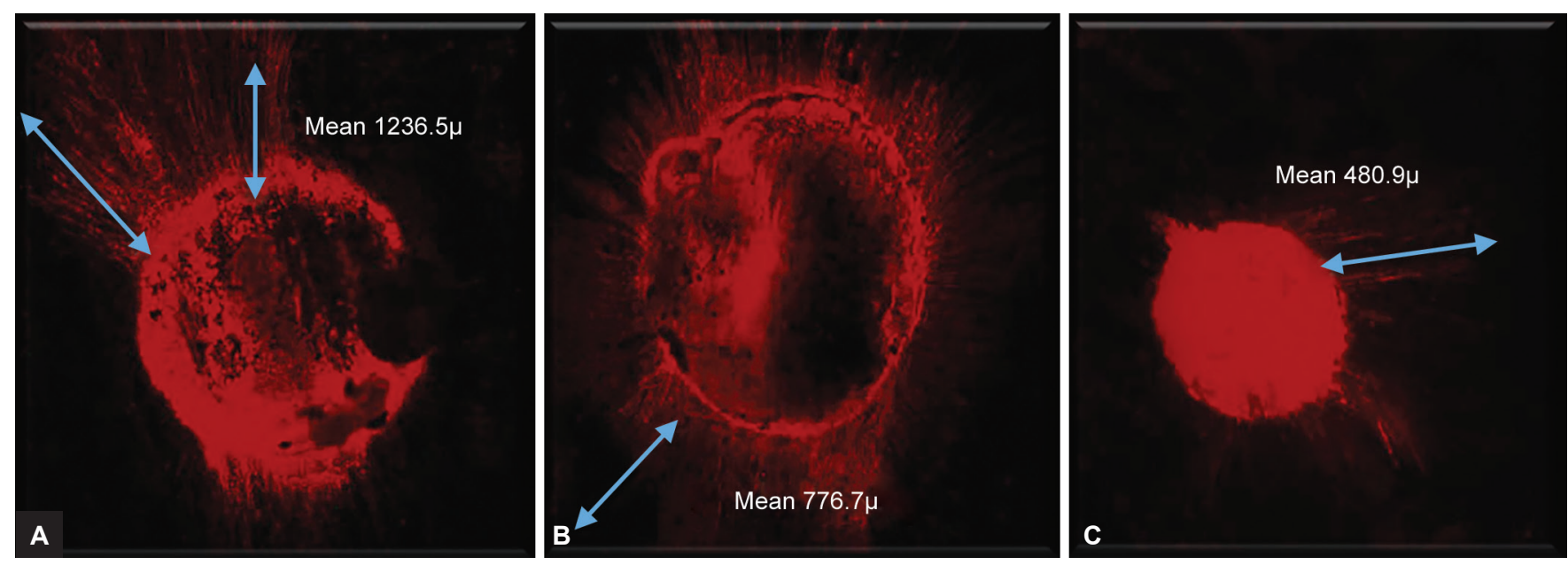

Figs $1 \mathrm{~A}$ to $\mathrm{C}$ : Representation of sealer penetration depth following the use of $17 \%$ aq. EDTA in: (A) Coronal; (B) middle; and (C) apical sections

Table 1: Descriptive statistical data of CLSM scores of the study groups

\begin{tabular}{|c|c|c|c|c|c|c|}
\hline & \multicolumn{2}{|c|}{ Coronal } & \multicolumn{2}{|c|}{ Middle } & \multicolumn{2}{|c|}{ Apical } \\
\hline & Mean & $S D$ & Mean & $S D$ & Mean & $S D$ \\
\hline EDTA & 236.48 & 29.58 & 776.65 & 25.49 & 480.94 & 20.34 \\
\hline Citric Acid & 1141.95 & 21.89 & 670.43 & 23.46 & 484.32 & 24.23 \\
\hline Maleic Acid & 953.30 & 20.34 & 551.62 & 36.88 & 386.43 & 39.22 \\
\hline $\mathrm{NaOCl}$ & 652.94 & 25.50 & 360.60 & 31.67 & 135.45 & 20.05 \\
\hline
\end{tabular}

SD: Standard deviation

Table 3: The Dunn's test for multiple comparison (also a nonparametric analysis) was used for comparisons within groups

\begin{tabular}{llll}
\hline & EDTA & Citric Acid & Maleic Acid \\
\hline Citric Acid & $0.016^{*}$ & - & - \\
Maleic Acid & $1.8 \mathrm{e}-07^{* *}$ & $3.4 \mathrm{e}-15^{* *}$ & - \\
$\mathrm{NaOCl}$ & $0.016^{*}$ & $3.1 \mathrm{e}-07^{* *}$ & $0.016^{*}$ \\
\hline
\end{tabular}

$\mathrm{P}$ value adjustment method: holm

The test returns the lower triangle of the matrix that contains the p-values of the pairwise comparisons.

Interpretations: The p-value less than that of 0.05 (*Significant,

${ }^{* *}$ Higher significance) indicates significance of difference in the respective pair.

\section{DISCUSSION}

The success of endodontic treatment depends largely on shaping and cleaning, disinfection, and 3D obturation. An age-old adage is that: "Files shape while irrigants clean." The primary aim of endodontic treatment is to eliminate all debris and microorganisms from the root canal system to prevent recontamination. ${ }^{11}$ The complex anatomy of the root canal system makes it impossible to completely disinfect the root canal using instrumentation alone. ${ }^{12}$ Irrigation is a critical and an essential complement to shaping and cleaning, since it penetrates canal irregularities and is important for removal of bacteria, debris, and necrotic tissue present in the smear layer. ${ }^{13}$ The smear layer comprises organic and inorganic substances derived from ground dentin and predentin; pulpal remnants; odontoblast processes; and, in cases of infected root canals, bacteria. ${ }^{4}$ It hinders effective penetration of antimicrobial
Table 2: The Kruskal-Wallis nonparametric test for comparison between groups

\begin{tabular}{llll}
\hline & Coronal & Middle & Apical \\
\hline Chi-square & 73.354 & 73.782 & 64.920 \\
Df & 3 & 3 & 3 \\
p-value & 0 & .0 & 0 \\
\hline
\end{tabular}

Df: Degrees of freedom

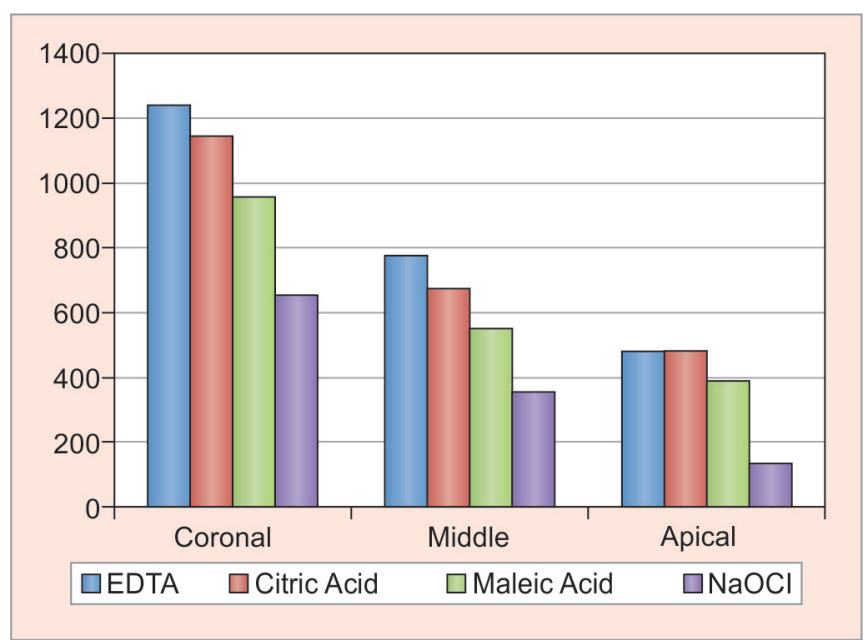

Graph 1: Comparison of sealer penetration in respective groups

agents and root canal sealers into dentinal tubules and has the potential of compromising the seal between root filling material and the root canal wall. ${ }^{14,15}$ For effective removal of smear layer, judicious use of chelating agents along with effective agitation methods is of paramount importance. ${ }^{4}$ Chelation is a chemical procedure involving formation of a heterocyclic ring compound that contains at least one metal cation or hydrogen ion in the ring. Chelating agents withdraw calcium from the inorganic calcium phosphate crystal lattice; this results in demineralization of the superficial dentin layer and exposure of collagen fibrils of the organic matrix. ${ }^{7}$ Chelating agents, such as EDTA, CA, MA, phosphoric acid, and combinations of EDTA and 
$\mathrm{NaOCl}$, have been used to remove the smear layer. ${ }^{4}$ Many studies have reported the penetration of sealer into root canal dentin. To analyze the extent of sealer penetration, SEM, light microscopy, and CLSM have been used. In the present study, CLSM was used because this technique has several advantages over SEM. ${ }^{9}$ In comparison with SEM and histologic methods, confocal microscopy has the advantage of providing detailed information about the presence and distribution of sealers or dental adhesives inside dentinal tubules in the total circumference of the root canal walls at magnification as low as $\times 50$ to $\times 100$ through the use of fluorescent dye-marked sealers. The principal advantage of CLSM is that it allows the study of a volume of dentin in nondehydrated specimens at the subsurface level of specimens using histotomographic images. ${ }^{16}$ The results of the present study showed that in all experimental groups the maximum depth of the sealer penetration was better in the coronal thirds than in the apical thirds of root canals. These results are in agreement with those of other studies. ${ }^{2}$ This could possibly be because there are more dentinal tubules in the coronal area, and the diameters of the tubules in the coronal area are larger than those in the apical area. In the present study, depth of sealer penetration was highest when final irrigation was carried out with $17 \%$ aqueous EDTA. This was also reported by other studies. ${ }^{17-19}$ The greater depth of sealer penetration could be attributed to the fact that EDTA reacts with the calcium ions in dentin and forms soluble calcium chelates. ${ }^{20}$ Eldeniz et $\mathrm{l}^{21}$ reported that $19 \%$ of CA is more efficient in reducing dentin microhardness than $17 \%$ EDTA, which differs from our results. It is known that the efficiency of a chelating agent depends on several factors, including application time, $\mathrm{pH}$, concentration, and the amount of solution. ${ }^{22}$ The depth of sealer penetration after the use of $10 \%$ CA was less than after the use of $17 \%$ EDTA, but more than $7 \% \mathrm{MA}$ and $5.25 \% \mathrm{NaOCl}$ solution, which is in accordance with other studies. ${ }^{9}$ Different techniques have been proposed to improve irrigant distribution within the root canal system. ${ }^{23}$ The PUI method is a noncutting irrigation protocol applied with ultrasonically activated files. ${ }^{24}$ Energy is transmitted from a file or smooth oscillating wire to the irrigation by ultrasonic waves, producing a stream and cavitation of the irrigating solution disrupting the vapor lock. Paragliola et $\mathrm{al}^{25}$ and Lui et $\mathrm{al}^{26}$ concluded that the use of ultrasonics with 17\% EDTA improved smear layer removal. De deus et $\mathrm{al}^{27}$ explained that the sealer penetration depth in the dentinal tubules also depends on various factors like dentinal permeability (the number and the diameter of tubules), root canal dimension, and the physical and chemical properties of the sealer. The flow is one of the main chemical/physical factors to influence the adaptation to the tubular penetration. AH Plus, an epoxy resin amine sealer, was used to carry out the obturation process because the flow of AH Plus is significantly higher than other sealers tested. ${ }^{28}$ Balguerie et $\mathrm{al}^{29}$ evaluated that AH Plus scores the best for adaptation to root canal wall, extent of tubular penetration, and adaptation to the peritubular dentin. This might be explained by the capillary action of the dentinal tubules. Sealer may be drawn into the tubules by capillary action and not by hydraulic forces created during root canal filling. AH Plus sealers have no fluorescent properties; hence, it was required to add a fluorescent rhodamine dye to the sealers to allow visualization under the CLSM. The sealer labeled with $0.1 \%$ rhodamine did not show changes in flow according to American Dental Association specifications. ${ }^{2}$ It is important to note that the obturation technique influences the percentage of sealer penetration into the root canal walls. Cold lateral compaction technique was used in this study. It was reported that the area of sealer-coated root canal wall in the coronal area was significantly higher when lateral condensation was used than vertical condensation. ${ }^{30}$ Furthermore, there was significantly more sealer in the lateral canals obturated using lateral condensation as measured by the ratio of gutta-percha and sealer in the main and lateral root canals.

\section{CONCLUSION}

Under the experimental conditions and within the limitations of this study, the following can be concluded based on the depth of sealer penetration:

- $17 \%$ aq. EDTA and 10\% CA can effectively remove smear layer from the coronal and middle third with no significant difference in the apical third

- $7 \%$ MA did not demonstrate significant depth of sealer penetration compared with the other chelating agents tested

- $5.25 \% \mathrm{NaOCl}$ is not efficient in smear layer removal

- None of the irrigating solutions tested were able to remove smear layer completely in the apical third of the root canal

- Activation with PUI shows potential to replace the conventional needle syringe delivery of irrigating solutions. It is important to emphasize that the results of this in vitro study cannot be directly extrapolated to all clinical conditions where the volume and exposure time of the irrigating solutions in the root canal may result in a different outcome.

\section{REFERENCES}

1. Musani I, Goyal V, Singh A, Bhat C. Evaluation and comparison of biological cleaning efficacy of two endofiles and irrigants as judged by microbial quantification in primary teeth-an in vivo study. Int J Clin Pediatr Dent 2009 SepDec;2(3):15-22. 
2. Tuncer AK, Tuncer S. Effect of different final irrigation solutions on dentinal tubule penetration depth and percentage of root canal sealer. J Endod 2012 Jun;38(6):860-863.

3. Scelza MF, Pierro V, Scelza P, Pereira M. Effect of three different time periods of irrigation with EDTA-T, EDTA and citric acid on smear layer removal. Oral Surg Oral Med Oral Pathol Oral Radiol Endod 2004 Oct;98(4):499-503.

4. Violich D, Chandler NP. The smear layer in endodontics - a review. Int Endod J 2010 Jan;43(1):2-15.

5. Dakshita J, Ashish A. Recent concepts on root canal chelation. ENDO (Lond Engl) 2011;5(3):175-194.

6. Hülsmann M, Heckendorff M, Lennon A. Chelating agents in root canal treatment: Mode of action and indications for their use. Int Endod J 2003 Dec;36(12):810-830.

7. Silva P, Guedes D, Nakadi F, Pécora JD, Cruz-Filho AM. Chitosan: a new solution for removal of smear layer after root canal instrumentation. Int Endod J 2013 Apr;46(4): 332-338.

8. Gu LS, Kim JR, Ling J, Choi KK, Pashley DH, Tay FR. Review of contemporary irrigant agitation techniques and devices. J Endod 2009 Jun;35(6):791-804.

9. Perdigão J, Lopes MM, Gomes G. Interfacial adaptation of adhesive materials to root canal dentin. J Endod 2007 Mar;33(3):259-263.

10. Ordinola-Zapata R, Bramante CM, Bernardineli N, Graeff MS, Garcia RB, de Moraes IG, Debelian G. A preliminary study of the percentage of sealer penetration in roots obturated with the Thermafil and RealSeal-1 obturation techniques in mesial root canals of mandibular molars. Oral Surg Oral Med Oral Pathol Oral Radiol Endod 2009 Dec;108(6):961-968.

11. Schilder, H.; Yee, FS. Canal debridement and disinfection. In: Cohen S.; Burns RC., editors. Pathways of the pulp. 3rd ed. The St. Louis: CV Mosby Company, 1984. p. 175.

12. Vertucci FJ. Root canal anatomy of the human permanent teeth. Oral Surg Oral Med Oral Pathol 1984 Nov;58(5): 589-599.

13. Abbott PV. Medicaments: aids to success in endodontics. Part 1. A review of the literature. Aust Dent J 1990 Oct;35(5): 438-448.

14. Lui J, Kuah H, Chen NN. Effect of EDTA with and without surfactants or ultrasonics on removal of smear layer. J Endod 2007 Apr;33(4):472-475.

15. Kuah HG, Lui JN, Tseng PS, Chen NN. The effect of EDTA with and without ultrasonics on removal of the smear layer. J Endod 2009 Mar;35(3):393-396.

16. D'Alpino PH, Pereira JC, Svizero NR, Rueggeberg FA, Pashley DH. Use of fluorescent compounds in assessing bonded resin-based restorations: a literature review. J Dent 2006 Oct;34(9):623-634.
17. Kirchhoff A L, Viapiana R, Miranda C, Sousa Neto MD, Cruz Filho AM. Comparison of the apple vinegar with other chelating solutions on smear layer and calcium ions removal from the root canal. Indian J Dent Res 2014 May-Jun;25(3):370-374.

18. Goldman LB, Bogis J, Cavalieri R, Lin PS. Scanning electron microscopic study of the effects of various irrigants and combinations on the walls of prepared root canals. J Endodon 1982;11:487-492.

19. Yamada RS, Armas A, Goldman M, Lin PS. A scanning electron microscopic comparison of a high volume final flush with several irrigating solutions. Part 3. J Endodon 1983 Apr;9(4):137-142.

20. Agrawal VS, Mahant R, Kapoor S, Patel M. A contemporary overview of endodontic irrigants - a review. J Dent App 2014;1(6): 105-115.

21. Eldeniz AU, Erdemir A, Belli S. Effect of EDTA and citric acid solutions on the microhardness and the roughness of human root canal dentin. J Endod 2005 Feb;31(2):107-110.

22. Cruz-Filho A, Sousa-Neto MD, Savioli RN, Silva RG, Vansan LP, Pécora JD. Effect of chelating solutions on the microhardness of root canal lumen dentin. J Endod 2011 Mar;37(3):358-362.

23. Lee Sj, Wu Mk, Wesselink PR. The effectiveness of ultrasonic irrigation to remove artificially placed dentine debris from different-sized simulated plastic root canals. Int Endod J 2004 Sep;37(9):607-612.

24. Van der Sluis LW, Versluis M, Wu MK, Wesselink PR. Passive ultrasonic irrigation of the root canal: a review of the literature. Int Endod J 2007 Jun;40(6):415-426.

25. Paragliola R, Franco V, Fabiani C, Mazzoni A, Nato F, Tay FR, Breschi L, Grandini S. Final rinse optimization: influence of different agitation protocols. J Endod 2010 Feb;36(2):282-285.

26. Lui JN, Kuah HG, Chen NN. Effect of EDTA with and without surfactants or ultrasonics on removal of smear layer. J Endod 2007 Apr;33(4):472-475.

27. De Deus GA, Gurgel-Filho ED, Maniglia-Ferreira C, Coutinho-Filho T. The influence of filling technique on depth of tubule penetration by root canal sealer: a study using light microscopy and digital image processing. Aust Endod J2004 Apr;30(1):23-28.

28. Siqueira JF, Favieri A, Gahyva SM, Moraes SR, Lima KC, Lopes HP. Antimicrobial activity and flow rate of newer and established root canal sealers. J Endod 2000 May;26(5):274-277.

29. Balguerie E, van der Sluis L, Vallaeys K, Gurgel-Georgelin M, Diemer F. Sealer penetration and adaptation in the dentinal tubules: A scanning electron microscopic study. J Endod 2011 Nov;37(11):1576-1579.

30. Wu MK, de Gee AJ, Wesselink PR. Effect of tubule orientation in the cavity wall on the seal of dental filling materials: an in vitro study. Int Endod J 1998 Sep;31(5):326-332. 